\title{
Synthetic Polypeptide Adsorption to Cu-IDA Containing Lipid Films: A Model for Protein-Membrane Interactions
}

\author{
M. S. Kent, \\ Sandia National Laboratories, Albuquerque, New Mexico, and Livermore, California \\ H. Yim, \\ Sandia National Laboratories, Albuquerque, New Mexico, and Livermore, California
}

J. K. Murton,

Sandia National Laboratories, Albuquerque, New Mexico, and Livermore, California

D. Y. Sasaki,

Sandia National Laboratories, Albuquerque, New Mexico, and Livermore, California

B. D. Polizzotti,

Department of Materials Science and Engineering, University of Delaware, Newark, Delaware

M. B. Charati,

Department of Materials Science and Engineering, University of Delaware, Newark, Delaware

K. L. Kiick,

Department of Materials Science and Engineering, University of Delaware, Newark, Delaware

I. Kuzmenko, and

Argonne National Laboratory, Argonne, Illinois

S. Satija

National Institute of Standards and Technology, Gaithersburg, Maryland

\section{Abstract}

Adsorption of synthetic alanine-rich peptides to lipid monolayers was studied by X-ray and neutron reflectivity, grazing incidence X-ray diffraction (GIXD), and circular dichroic spectroscopy. The peptides contained histidine residues to drive adsorption to Langmuir monolayers of lipids with iminodiacetate headgroups loaded with $\mathrm{Cu}^{2+}$. Adsorption was found to be irreversible with respect to bulk peptide concentration. The peptides were partially helical in solution at room temperature, the temperature of the adsorption assays. Comparisons of the rate of binding and the structure of the adsorbed layer were made as a function of the number of histidines (from 0 to 2 ) and also as a function of the positioning of the histidines along the backbone. For peptides containing two histidines on the same side of the helical backbone, large differences were observed in the structure of the adsorbed layer as a function of the spacing of the histidines. With a spacing of $6 \AA$, there was a substantial increase in helicity upon binding (from $17 \%$ to $31 \%$ ), and the peptides adsorbed to a final density approaching that of a nearly completed monolayer of $\alpha$-helices adsorbed side-on. The thickness of the adsorbed layer $(17 \pm 2.5 \AA)$ was slightly greater than the diameter of $\alpha$-helices, suggesting that the free, unstructured ends extended into solution. With a spacing of $30 \AA$ between histidines, a far weaker increase in helicity upon binding was observed (from 13\% to 19\%) and a much lower packing

Correspondence to: M. S. Kent.

Supporting Information Available: Additional figures as described in the text. This material is available free of charge via the Internet at http://pubs.acs.org. 
density resulted. The thickness of the adsorbed layer $(10 \pm 4 \AA)$ was smaller, consistent with the ends being bound to the monolayer. Striking differences were observed in the interaction of the two types of peptide with the lipid membrane by GIXD, consistent with binding by two correlated sites only for the case of $6 \AA$ spacing. All these results are attributed to differences in spatial correlation between the histidines as a function of separation distance along the backbone for these partially helical peptides. Finally, control over orientation was demonstrated by placing a histidine on an end of the sequence, which resulted in adsorbed peptides oriented perpendicular to the membrane.

\section{Introduction}

The use of proteins and biomacromolecules of controlled structure is of increasing interest in biotechnology and materials design, and opportunities to integrate biological molecules with organic and inorganic systems offer great promise in device technology. Controlling binding affinity, orientation, and conformation in the interactions of biological analytes with lipid membranes is important for sensing, for stimulating the formation of specific supramolecular structures useful for nanoscience applications, for developing synthetic signaling systems, and for biophysical studies. ${ }^{1-3}$ A specific example is the localization of antibodies to substrates in biosensors in orientations that expose the binding sites. Understanding in more detail the processes by which proteins and peptides adsorb to membranes and surfaces will therefore benefit many important technological applications. In addition, insights into the interaction of soluble proteins with defined membranes may also provide insight into the interactions that guide the association and complex formation that drive cellular function. ${ }^{4,5}$ Such interactions tend to be dictated by specific ligation through single and multiple point binding that drive membrane reorganization in the formation of complexes for signaling and cellular uptake, or for structure and stabilization. In some cases, conformational changes of proteins are induced upon binding. ${ }^{6}$ While the identities of the numerous constituents are still being mapped out, the specific as well as nonspecific interactions that guide the association and complex formation remain incompletely understood.

Model systems enable a detailed study of the role of specific and nonspecific interactions and their effects on binding affinities and protein conformations. One available method to localize proteins and peptides to lipid membranes, or to surfaces in general, is to use the interaction of histidines with divalent metal ions. The use of metal ion coordination to target the adsorption of proteins to lipid membranes has received much attention previously. ${ }^{1,7-19}$ Mixtures of metal-chelating lipids with other lipids are being investigated for protein detection schemes, as protein adsorption can lead to in-plane rearrangements of the lipids detectable by fluorescence techniques. ${ }^{12,13}$

The present study explored adsorbed peptide structures involving the $\alpha$-helix motif. It involved partially helical peptides that interacted with lipid membranes through divalent metal ionhistidine interactions. Many previous studies have shown an increase in the helicity of peptides upon insertion into lipid bilayers. ${ }^{20-23}$ In contrast to these studies, the present study involved peptides that did not insert, but rather adsorbed as a result of specific binding sites placed along the backbone. We examined the effects of one versus two histidines, as well as the placement of the histidines along the sequence, on the orientation, conformation, and extent of helicity for the adsorbed peptides. We show below that, although the peptides adopted similar conformations in solution, the adsorbed conformations were substantially different.

We used circular dichroic (CD) spectroscopy to determine the helicity of the peptides in solution and also bound to liposomes, and X-ray and neutron reflectivity (XR and NR) to study the structure of the peptides upon adsorption to lipid monolayers. We also included grazing incidence X-ray diffraction (GIXD) in this study. Previous work showed that GIXD can reveal 
subtle differences in the mode of interaction of proteins with lipid monolayers. ${ }^{24}$ In particular, disruption of the lipid gel phase occurred upon binding of proteins by multiple sites, whereas binding of proteins by a single site had little or no detectable effect on the ordered packing of the lipid tails. Therefore, we included GIXD in this study to determine whether changes in lipid packing might also be induced upon binding of the present peptides as a function of the placement of histidine residues along the peptide backbone.

\section{Experimental Section}

\section{Materials}

Fmoc-protected amino acids and other chemicals for solid-phase peptide synthesis were obtained from Novabiochem (San Diego, CA). Solvents for HPLC purification were obtained from Sigma-Aldrich (St. Louis, MO). The synthesis of 1,2-disterylglycero-3triethyleneoxideiminodiacetic acid (DSIDA) has been described previously. ${ }^{17} \mathrm{CuCl}_{2}$ $(99.999 \%)$ and $\mathrm{D}_{2} \mathrm{O}$ (99.9\%) were purchased from Aldrich. Chloroform used for spreading the lipid monlayers was purchased from Fluka. The phosphate buffer solution (PBS) was prepared by dissolving $8.16 \mathrm{~g}$ sodium hydrogen phosphate heptahydrate (Aldrich), $1.20 \mathrm{~g}$ sodium dihydrogen phosphate monohydrate (Aldrich), and $5.86 \mathrm{~g}$ sodium chloride (Aldrich) in $1 \mathrm{~L}$ of Millipore water (18 $\mathrm{M} \Omega$ resistivity), which resulted in a $\mathrm{pH}$ of 7.2-7.3.

\section{Methods}

Synthesis of Peptides-Peptides 1-5 were prepared on Rink Amide MBHA resin via automated Fmoc peptide synthesis employing a PS3 peptide synthesizer (Protein Technologies, Inc., Tucson, AZ) and HBTU activation. The resulting dry resin-bound peptides were cleaved and side chains deprotected using TFA/water/1,2-ethanedithiol/triisopropylsilane

(94.5:2.5:2.5:1). Crude peptides were subsequently dissolved in minimal water and purified via RP-HPLC using a preparative Symmetry C18 peptide/protein column and HPLC solvents consisting of solvent $\mathrm{A}(0.1 \%$ TFA in water) and solvent $\mathrm{B}(0.1 \%$ TFA in acetonitrile) with a linear gradient from $5 \%$ to $70 \% \mathrm{~B}$ over $49 \mathrm{~min}$. The resultant pure peptides were characterized via mass spectrometry. MALDI-TOF analysis of purified peptides was performed at the Mass Spectrometry Facility in the Department of Chemistry and Biochemistry at the University of Delaware on a Biflex III (Bruker, Billerica, MA). The samples were prepared in a 3,5-

dimethoxy-4-hydroxycinnamic acid matrix. Data were recorded with the OmniFLEX program and subsequently analyzed in the XmassOmni program. The analysis yielded the following: $\mathrm{P} 1$, calculated $(\mathrm{M}+\mathrm{H})^{+}$3048.19, observed $(\mathrm{M}+\mathrm{H})^{+}$3055.84; $\mathrm{P} 2$ calculated $(\mathrm{M}+\mathrm{H})^{+}$3037.30, observed $(\mathrm{M}+\mathrm{H})^{+}$3041.41; $\mathrm{P} 3$, calculated $(\mathrm{M}+\mathrm{H})^{+}$3066.21, observed $(\mathrm{M}+\mathrm{H})^{+}$3067.37; $\mathrm{P} 4$, calculated $(\mathrm{M}+\mathrm{H})^{+}$3037.30, observed $(\mathrm{M}+\mathrm{H})^{+}$3036.20; $\mathrm{P} 5$, calculated $(\mathrm{M}+\mathrm{H})^{+}$3028.28, observed $(\mathrm{M}+\mathrm{H})^{+} 3037.00$.

Determination of Peptide Concentration in the CD Studies-The peptide concentration was determined from the extinction coefficient of tryptophan. Briefly, a stock solution of peptide was serially diluted in $10 \mathrm{mM}$ phosphate buffer at a $\mathrm{pH}$ of 7.0. Then, using a $1 \mathrm{~cm}$ cell, the absorption of the diluted peptide solutions was collected at a wavelength of $280 \mathrm{~nm}$. The concentration $(\mathrm{mg} / \mathrm{mL})$ of the stock solution was then calculated using the equation $[\mathrm{mg} / \mathrm{mL}$ peptide $]=($ A.U. $\times \mathrm{DF} \times \mathrm{MW}) / \mathrm{n} \varepsilon_{\mathrm{W}, 280 \mathrm{~nm}}$ where A.U. is the absorption at $280 \mathrm{~nm}, \mathrm{DF}$ is the dilution factor, MW is the molecular weight of the peptide, and $\mathrm{n} \varepsilon_{\mathrm{W}, 280 \mathrm{~nm}}$ is the number of tryptophan residues per peptide multiplied by the molar extinction coefficient of tryptophan at $280 \mathrm{~nm}(5560 \mathrm{AU} / \mathrm{mmol} / \mathrm{mL})$.

Preparation of DSIDA/Cu${ }^{2+}$ Liposomes-Liposomes of DSIDA loaded with $\mathrm{Cu}^{2+}$ were prepared as follows. A $2 \mathrm{mM}$ solution of DSIDA in chloroform was dried down to a thin film on the sides of a conical tube under vacuo using a rotory evaporator, then further dried under 
vacuum overnight. The dried films were rehydrated with $3 \mathrm{~mL}$ of phosphate buffer, and then sonicated at a power of $10 \mathrm{~W}$ to yield small unilamellar vesicles (SUVs). The vesicle solution was then centrifuged at $16000 \mathrm{rpm}$ for $20 \mathrm{~min}$ followed by filtration through a $0.20 \mu \mathrm{m}$ nylon membrane to remove aggregates and particles. Dilution with phosphate buffer afforded a total lipid concentration of $100 \mu \mathrm{M}$. $\mathrm{Cu}^{2+}$ was then loaded into the bilayers by addition of aqueous solutions of $\mathrm{CuCl}_{2}$. An average hydrodynamic radius of $33 \mathrm{~nm}$ for the liposomes was measured by dynamic light scattering.

CD Spectroscopy-CD spectra were recorded on a JASCO 810 spectrophotometer (Jasco, Inc., Easton, MD) in a $1 \mathrm{~mm}$ path length quartz cuvette in the single-cell mount setup. For measurements of free peptide in solution, background scans of buffer were recorded and subtracted from the sample scans. Samples were made by dilution to $0.3 \mathrm{mg} / \mathrm{mL}(100 \mu \mathrm{M})$ from a $1 \mathrm{mg} / \mathrm{mL}$ stock solution of peptide in PBS buffer $\mathrm{pH}$ 7.2. The samples $(400 \mu \mathrm{L})$ were loaded into a $1 \mathrm{~mm}$ path length quartz cuvette. For $\mathrm{CD}$ measurements of peptide in the presence of DSIDA/ $\mathrm{Cu}^{2+}$ liposomes, a $1 \mathrm{~cm}$ path length cell was used. The DSIDA and peptide concentrations were $100 \mu \mathrm{M}$ and $4 \mu \mathrm{M}$, respectively. Background scans were made of the liposomes in buffer and subtracted from the sample scans. Data points for the wavelengthdependent CD spectra were recorded at every nanometer with a $1 \mathrm{~nm}$ bandwidth, scanning speed of $50 \mathrm{~nm} / \mathrm{s}$, and an averaging time for each data point that ranged from 4 to $10 \mathrm{~s}$.

X-ray Reflectivity and Grazing Incidence X-ray Diffraction-XR measurements were performed using the liquid surface spectrometer on beamline ID-9 at the Advanced Photon Source (CMC-CAT, Argonne National Laboratory) and an in-house X-ray reflectometer (Bruker) employing $\mathrm{Cu} \mathrm{K} \alpha$ radiation at NIST (Gaithersburg, MD). NR data were collected using the NG7 reflectometer at NIST. For the XR, NR, and GIXD measurements, the liquid was contained in a Teflon trough with a movable barrier. For all measurements, the trough was contained inside a closed canister to minimize evaporation. The measurements were made at $22 \pm 2{ }^{\circ} \mathrm{C}$. For GIXD, a plate of glass was introduced just below the meniscus of the subphase, which substantially reduced the surface waves. Also, the trough container was continuously purged with helium to minimize oxidative degradation of the organic monolayer in the presence of the intense X-ray beam and to reduce background scattering. The techniques for preparing the monolayers and circulating the metal ions and peptides underneath the monolayer have been described previously. ${ }^{25,26}$ Briefly, in a typical adsorption run DSIDA was spread in the form of a monolayer to a surface pressure of $8-10 \mathrm{mN} / \mathrm{m}$ on the surface of PBS held within a Teflon trough. After allowing the chloroform to evaporate, the surface layer was compressed to $40 \mathrm{mN} / \mathrm{m}$ and the surface area was then held constant as $\mathrm{CuCl}_{2}$ solution was added to the subphase to a concentration of $10 \mu \mathrm{M}$. The subphase was circulated using a peristaltic pump and Teflon tubing with an inlet and outlet submerged at opposite ends of the trough. The subphase was circulated at least twice to achieve complete mixing. Upon circulation of the $\mathrm{CuCl}_{2}$ solution, the pressure dropped as chelation of $\mathrm{Cu}^{2+}$ ions reduced the negative charge on the headgroups. After this drop in surface pressure, the monolayer was compressed further to recover a pressure of $40 \mathrm{mN} / \mathrm{m}$. For XR and NR, the barrier position was then held fixed, and the peptide was injected into the subphase and circulated. Little or no change in surface pressure occurred upon peptide binding. For GIXD, the surface layer was maintained at $40 \mathrm{mN} / \mathrm{m}$. Little or no change in area occurred upon peptide binding. Subphase dilution was accomplished by simultaneously pumping the subphase out from one end of the trough into a reservoir and pumping from the reservoir into the subphase underneath the monolayer at the other end of the trough. Precise control of the two rates allowed the meniscus and the adsorbed layer to remain undisturbed during the process. The reflectivity data were normalized using the critical edge for total reflection and are presented as $R \times q_{z}^{4}$ to most clearly reveal the structural features in the data by removing the $q_{z}^{-4}$ dependence of the Fresnel law for ideal interfaces. 
The reflectivity data were analyzed using a least-squares fitting procedure involving multilayer models. ${ }^{27,28} \mathrm{XR}$ data for the metal ion-loaded DSIDA in the absence of peptide required three slabs in the model electron density profile. The electron density and thickness of the tail layer were constrained to be consistent with the known area per molecule of $40 \AA^{2}$ at $40 \mathrm{mN} / \mathrm{m}$ from the pressure-area isotherm ${ }^{15}$ and the atomic composition of DSIDA. With the peptide present, an additional layer was added to the profile. The uncertainty in the thickness of the adsorbed layer was determined by fixing that parameter at various values and allowing the other parameters to vary in the fitting within physically reasonable limits. Upper and lower bounds were determined by the values that led to fits which were unacceptably poor as judged by an increase in $\chi^{2}$ by a factor of 1.1. The reported thicknesses were obtained as the minima in plots of $\chi^{2}$ versus thickness.

GIXD was performed on the liquid surface spectrometer on beamline ID-9 at the Advanced Photon Source. ${ }^{28-30}$ To maximize surface sensitivity for GIXD measurements, the monochromatic X-ray beam was adjusted to strike the surface at an incident grazing angle $\alpha_{\mathrm{i}} \sim 0.1^{\circ}$, which corresponds to the vertical momentum transfer vector $q_{z}=0.85 q_{\mathrm{c}}$, where $q_{\mathrm{c}}=0.0218 \AA^{-1}$ is the critical scattering vector for total external reflection from a water surface. For $q_{z}<q_{\mathrm{c}}$, the incident wave is totally reflected from the sample, and an evanescent wave travels along the interface. The intensity of the evanescent wave decreases exponentially with depth, thus enhancing the surface sensitivity and reducing the background scattering from the subphase. For the GIXD measurements, the dimensions of the footprint of the incoming X-ray beam on the liquid surface were $\sim 2 \times 50 \mathrm{~mm}^{2}$. For the collection of diffracted intensities, a vertical one-dimensional position sensitive detector (PSD) with vertical acceptance $0<q_{z}<$ $1.0 \AA^{-1}$ was used. A Soller collimator was mounted in front of the PSD, defining the horizontal resolution of the detector at $\Delta q_{x y}=0.009 \AA^{-1}$. The scattered intensity was measured by scanning over a range of the horizontal scattering vector component

$q_{x y}=\left(q_{x}^{2}+q_{y}{ }^{2}\right)^{1 / 2}=\frac{2 \pi}{\lambda}\left[\cos ^{2}\left(\alpha_{i}\right)+\cos ^{2}\left(\alpha_{f}\right)-2 \cos \left(\alpha_{i}\right) \cos \left(\alpha_{f}\right) \cos 2 \theta_{x y}\right]^{1 / 2} \approx(4 \pi / \lambda) \sin \left(2 \theta_{x y} / 2\right)$

where $2 \theta_{x y}$ is the angle between the incident and diffracted beam projected onto the horizontal plane, and $q_{x y}$ is the combination of horizontal components $q_{x}$ and $q_{y} .30$ Such a scan, integrated over all the channels along the $q_{z}$ direction in the PSD, yields the Bragg peaks.

\section{Results}

\section{Peptide Design and Characterization}

Our primary interest was the design of flexible helical peptides that carried a specific number of metal-ion ligating residues for interaction with the $\mathrm{Cu}^{2+}$-IDA functionality presented by the lipid film, and so we focused on the production of alanine-rich sequences containing histidine residues. In these studies, the general sequence (AAQAA) ${ }_{x}$ was chosen for investigation on the basis of the high helical propensity of alanine and the helix forming tendency and water solubility of glutamine. Alanine has the highest helical propensity of the natural amino acids, and a variety of alanine-rich peptides and polypeptides have been studied previously. ${ }^{31-35}$

The sequences chosen for this study, shown in Table 1, share the same generic backbone but differ in the number, spacing, and orientation of histidine residues. For example, P2 and P3 were designed to present histidine residues along the same face of the helical backbone in a completely helical construct. The nominal distance between histidine residues was varied from approximately 6 (P2) to $30 \AA$ (P3) to probe the effect of distance between active binding sites interacting with the lipid membrane. 
CD spectroscopy confirmed that the free peptides had partially helical conformations in solution. The mean residue ellipticity ([ $[\theta])$ as a function of wavelength was recorded for solutions of the various peptides in $10 \mathrm{mM}$ phosphate buffer at a $\mathrm{pH}$ of 7.2, as a function of increasing temperature. The results for $\mathrm{P} 2$ are shown in Figure 1 . At $5{ }^{\circ} \mathrm{C}$, the spectra exhibit minima at 208 and $222 \mathrm{~nm}$. Increasing the temperature results in gradual loss of the minimum at $222 \mathrm{~nm}$ and a shift of the lower wavelength minimum from 208 to $198 \mathrm{~nm}$. The form of these spectra are consistent with results reported for similar alanine-rich peptides, ${ }^{31,35}$ indicating that the peptide adopts a partially $\alpha$-helical conformation at temperatures below 30 ${ }^{\circ} \mathrm{C}$ and a non-helical conformation above $30^{\circ} \mathrm{C}$.

Upon cooling the peptide solution back down to $5{ }^{\circ} \mathrm{C}$, the minima at 208 and $222 \mathrm{~nm}$ reappear without any loss in the $[\theta]$, indicating a completely reversible process as expected for these sequences. Similar results were obtained for the other peptides. The ratio of the $[\theta]$ at 222 and $208 \mathrm{~nm}\left([\theta]_{222} /[\theta]_{208}\right)$ at $5{ }^{\circ} \mathrm{C}$ is approximately 1.1 for $\mathrm{P} 2$ and $\mathrm{P} 3$, consistent with values of $1.1-1.3$ for helical, hydrated, and nonaggregated alanine-rich peptides. ${ }^{36-38}$ The $[\theta]$ at $222 \mathrm{~nm}$ for $\mathrm{P} 2$ and $\mathrm{P} 3$ at $5{ }^{\circ} \mathrm{C}$ are approximately -18500 and $-12500 \mathrm{deg} \mathrm{cm}^{2} \mathrm{dmol}^{-1}$, respectively, comparable to the $[\theta]_{222}$ values of -5500 to $-15100 \mathrm{deg} \mathrm{cm}^{2} \mathrm{dmol}^{-1}$ previously reported for alanine-rich peptides comprising 15 amino acids. ${ }^{31}$

The degree of helicity in alanine-rich peptides is length-dependent and can be calculated using the following equation ${ }^{39}$

$$
\text { helix content }=\frac{[\theta]_{222(\text { obs. })}}{[\theta]_{222(\text { Max })}} \text { and }[\theta]_{222(\text { Max })}=-61000(1-2.5 / n)
$$

where $[\theta]_{222(\mathrm{Obs})}$ is $[\theta]$ at $222 \mathrm{~nm}$ for the peptide of interest and $[\theta]_{222(\mathrm{Max})}$ is the theoretical $[\theta]$ for short alanine-rich peptides with $n$ amino acids. For values of -18500 and $-12500 \mathrm{deg}$ $\mathrm{cm}^{2} \mathrm{dmol}^{-1}$ for $[\theta]_{222(\mathrm{Obs})}$ and 34 and 33 for $n$, the helicity values were determined to be approximately $33 \%$ and $22 \%$ for $\mathrm{P} 2$ and $\mathrm{P} 3$, respectively, in solution at $5{ }^{\circ} \mathrm{C}$. At $25{ }^{\circ} \mathrm{C}$, the helicity values of the free peptides in solution were reduced to approximately $17 \%$ and $13 \%$, respectively. These results are similar to results for other (AAQAA) sequences. $^{31,35}$

Noncovalent aggregation at elevated concentrations caused by the high degree of hydrophobicity is a potential problem with alanine-rich peptides. Therefore, temperaturedependent $\mathrm{CD}$ spectra were acquired at two concentrations that spanned the range of concentrations employed in the XR, NR, and GIXD studies to determine if the peptides were subject to any concentration-dependent aggregation. [ $\theta$ ] at $222 \mathrm{~nm}$ was monitored as a function of temperature for the solutions of $\mathrm{P} 2$ and $\mathrm{P} 3$ in $10 \mathrm{mM}$ phosphate buffer at a $\mathrm{pH}$ of 7.2. The results for P2 and P3 (shown in Figure 1a,b, respectively, of the Supporting Information) show that as the temperature increases the absolute magnitude of $[\theta]_{222}$ decreases, whereas no significant change in $[\theta]_{222}$ occurs with peptide concentration. These results are similar to those seen for other nonaggregating alanine-rich peptides, ${ }^{35}$ suggesting that this system does not undergo significant noncovalent aggregation in the concentration range examined in this study.

\section{Spectroscopy of Peptides Bound to DSIDA/Cu${ }^{2+}$ Liposomes}

CD spectra were acquired for P2, P3, and P5 in the presence of liposomes of DSIDA/ $\mathrm{Cu}^{2+}$ for comparison with the spectra of the free peptides in solution. Percent helicity was again determined using eq 2. For P2 and P3 the absolute magnitude of $[\theta]_{222}$ increased with time in the presence of DSIDA/ $\mathrm{Cu}^{2+}$ liposomes, indicating that the fractional helicity of the peptides increased upon binding. In contrast, the absolute magnitude of $[\theta]_{222}$ decreased slightly with time for the free peptides in solution. To allow ample time for the peptides to bind to the 
liposomes, final CD spectra were recorded after $20 \mathrm{~h}$, at which point the spectra were no longer changing. Since the liposome concentration $(100 \mu \mathrm{M})$ was sufficient to provide more than enough surface area for all the peptide in solution to bind, and as discussed below the binding of the peptides to DSIDA/ $\mathrm{Cu}^{2+}$ is irreversible at room temperature, we believe that the $\mathrm{CD}$ spectra after $20 \mathrm{~h}$ in the presence of the liposomes represent those of bound peptide with little free peptide in solution. The spectra for P2 and $\mathrm{P} 3$ after $20 \mathrm{~h}$ with and without DSIDA/Cu $\mathrm{Cu}^{2+}$ liposomes present are shown in Figure 2a,b. In the presence of DSIDA/Cu ${ }^{2+}$ liposomes, the percent helicity of $\mathrm{P} 2$ was $31 \%$ whereas that for free $\mathrm{P} 2$ in solution was $17 \%$. For $\mathrm{P} 3$, the helicity after $20 \mathrm{~h}$ in the presence of DSIDA/ $\mathrm{Cu}^{2+}$ liposomes was $19 \%$, whereas that for free $\mathrm{P} 3$ in solution was $13 \%$. These results show that the increase in fractional helicity upon binding to DSIDA/ $\mathrm{Cu}^{2+}$ was much greater for $\mathrm{P} 2$ than for P3. A much smaller change was observed for P5 upon binding to the liposomes, as shown in Figure 2c. The helicity of P5 after $20 \mathrm{~h}$ in the presence of DSIDA $/ \mathrm{Cu}^{2+}$ vesicles was $17 \%$, whereas that for free P5 in solution was $14 \%$.

\section{X-ray and NR Reflectivity}

XR data were collected before and after adsorption of P2 (at $14 \mu \mathrm{M}$ ), P3 (at $14 \mu \mathrm{M}$ ), and P5 (at $10 \mu \mathrm{M}$ ) to $\mathrm{Cu}^{2+}$-loaded DSIDA. In the case of P3, the peptide was added in several increments to reach the final bulk concentration. The full curves obtained out to $q_{z}=0.5 \AA^{-1}$ are shown in Figure 3a, Figure 1 of the Supporting Information, and Figure 2 of the Supporting Information, respectively. Changes at the lower $q_{z}$ values most strongly reflect the characteristics of the adsorbed peptide, and an expanded view of this region in each case is shown in Figure 3b, Figure 4a, and Figure 5a. The decrease in reflectivity at the higher $q_{z}$ values reflects mainly increased roughness of the lipid membrane. The corresponding fitted electron density profiles are shown in Figure 3c, Figure 4b, and Figure 5b. The data in Figures 3-5 demonstrate that XR can detect the presence of the adsorbed peptides. Moreover, close comparison reveals differences in the three cases that correspond to structural differences in the adsorbed layers. In particular, the increase in XR in the range of $q_{z}$ from $0.03 \AA^{-1}$ to 0.07 $\AA^{-1}$ upon adding peptide is significantly greater for $\mathrm{P} 2$ than for $\mathrm{P} 3$, and with $\mathrm{P} 5$, the reflectivity crosses that for $\mathrm{Cu}^{2+}$-loaded DSIDA at a much lower $q_{z}$ value than for P2 and P3. As a control, $\mathrm{XR}$ data were collected before and after adsorption of $\mathrm{P} 1$ (no histidines) at $10 \mu \mathrm{M}$ to $\mathrm{Cu}^{2+}$ loaded DSIDA. The data (provided in Figure 4 of the Supporting Information) show that very little nonspecific adsorption occurs in the absence of His residues on the peptides. Finally, we note that the adsorbed peptides can also be detected with neutron reflection. NR data before and after adsorption of P3 (at $14 \mu \mathrm{M}$ ) to $\mathrm{Cu}^{2+}$-loaded DSIDA from a phosphate-buffered $\mathrm{D}_{2} \mathrm{O}$ suphase are shown in Figure 6. In this case, the entire quantity of peptide was added in a single injection. The inset shows the $\chi^{2}$ analysis from which a thickness of $27 \pm 7 \AA$ was determined.

Adsorbed amounts determined by integrating the electron density profiles are plotted as a function of time in Figure 7 for several of the peptides. Data are shown for P2 at $4 \mu \mathrm{M}$ and 14 $\mu \mathrm{M}, \mathrm{P} 3$ at $4 \mu \mathrm{M}$, and $\mathrm{P} 4$ at $4 \mu \mathrm{M}$. The adsorbed amount increases over time for P2 at $4 \mu \mathrm{M}$, which contrasts with the results for $\mathrm{P} 3$ and $\mathrm{P} 4$, which are largely independent of time. We show below that adsorption is irreversible at the conditions of these studies, so a constant adsorbed amount indicates saturation of the surface. The surface saturates at a much greater adsorbed amount for P2 $\left(\sim 17\right.$ molecules $\left./(100 \AA)^{2}\right)$ than for P3 or P4 $\left(\sim 4\right.$ molecules $/(100 \AA)^{2}$, indicating that $\mathrm{P} 2$ adopts a much different conformation upon adsorption than the other two peptides. Although membrane-bound $\mathrm{P} 2$ is only $31 \%$ helical as shown by $\mathrm{CD}$, the packing density is high, with the adsorbed amount at $14 \mu \mathrm{M}$ approaching the calculated value for the peptides in an $\alpha$-helical conformation adsorbed side-on and packed at close-packed density (19 molecules/ $(100 \AA)^{2}$ ).

Adsorbed amounts for $\mathrm{P} 2$ and $\mathrm{P} 3$ are shown in Figure 8 as a function of bulk concentration. In one series of runs, the peptide concentration was increased successively and XR data were 
collected at $1 \mu \mathrm{M}, 4 \mu \mathrm{M}, 7 \mu \mathrm{M}$, and $14 \mu \mathrm{M}$ with little delay time between each addition beyond the $3 \mathrm{~h}$ required to collect the data. The data for these runs are shown as circles in Figure 8. For P2 (filled circles), two successive XR scans were performed at $4 \mu \mathrm{M}$ before the subsequent addition of peptide. The results of both scans are shown in Figure 8 where the higher adsorbed amount corresponds to the second scan. In this case, the adsorbed amount increased substantially throughout the entire series of peptide additions. For the analogous study involving P3 (open circles), very little change in adsorbed amount was observed beyond 4 $\mu \mathrm{M}$, which again indicates saturation of the surface by P3 at $\sim 4$ molecules $/(100 \AA)^{2}$. Following the XR scan for P3 at $14 \mu \mathrm{M}$, the subphase was diluted to $2.3 \mu \mathrm{M}$. Very little change in the XR data was detected for a period of $14 \mathrm{~h}$ following dilution. The data are provided in Figure 5 of the Supporting Information. This indicates that adsorption is irreversible with respect to bulk concentration for the conditions of the present study. As reported elsewhere, a similar result was observed for lysozyme (single exposed histidine) adsorbed to DSIDA loaded with $\mathrm{Cu}^{2+}$. ${ }^{24}$ This is consistent with the fact that the binding energy per site is $\sim 8 \mathrm{kT} .{ }^{26}$ Other work has shown that, at room temperature, interactions transition from reversible to irreversible over the range 1-4 kT..$^{40,41}$ In a second series of runs, the entire mass of peptide was injected from the start to achieve a bulk concentration of $14 \mu \mathrm{M}$. The data for P2 (XR) and P3 (NR) are shown as triangles in Figure 8. For P2, the adsorbed amounts are comparable for the two modes of addition. For P3, a higher adsorbed amount resulted when the entire mass of peptide was injected from the start.

Thicknesses of the adsorbed layers for P2 and P3 are plotted in Figure 9a as a function of bulk concentration for the series involving successive additions (indicated by circles) as well as the runs in which the entire quantity of peptide was injected from the start (triangles). Error bars were determined from the fitting analysis by fixing the thickness and allowing the other parameters to vary within physically reasonable limits. Upper and lower bounds were determined by the thickness values that resulted in an increase in $\chi^{2}$ by a factor of 1.1. Examples are shown for P2 and P3 in Figure 9b,c, respectively. The layer thicknesses for P2 $(\sim 17 \AA)$ are slightly greater than the diameter of an $\alpha$-helix (with side chains) ( $12 \AA$, for example, 2 MLT in PDB). Since a side-on orientation is expected for this peptide based on the location of the histidines, this result suggests that the unstructured ends extend into solution beyond the diameter of the $\alpha$-helix. The thickness was independent of bulk concentration and did not depend upon the mode of addition (incremental or entire quantity in one injection). The values for P3 when added incrementally are noticeably smaller than the layer thicknesses for P2. However, when the entire mass of $\mathrm{P} 3$ was added from the start, a much greater layer thickness of $27 \pm 7 \AA$ was obtained, indicating that P3 binds in a different conformation depending upon its concentration in solution. The fact that for $\mathrm{P} 3$ different adsorbed layers resulted for different ways of achieving the same bulk concentration is further evidence that His- $\mathrm{Cu}^{2+}$-IDA interactions are irreversible at the present conditions, and that the peptides do not equilibrate with the bulk solution. Finally, for P5, which contains only a single histidine located at one end of the sequence, the thickness upon adsorption was much greater than for P2. Figure 10 displays the adsorbed amount versus time after injection of P5 at $10 \mu \mathrm{M}$. The inset shows that a thickness of $48 \pm 4 \AA$ was obtained after $40 \mathrm{~h}$, which is consistent with an end-on orientation for this peptide as opposed to the side-on orientation for P2. The slow time-scale for adsorption of $\mathrm{P} 5$ contrasts with the much more rapid adsorption for $\mathrm{P} 2$ at $14 \mu \mathrm{M}$.

\section{Grazing Incidence X-ray Diffraction}

Scans of the Bragg peak corresponding to the hexagonal packing of the DSIDA tails in gel phase are shown in Figure 11a as a function of time after injection of P2 at $10 \mu \mathrm{M}$. Normalized peak intensity is plotted as a function of time after injection in Figure 11b. Roughly $2 \mathrm{~h}$ after injection, the Bragg peak nearly entirely disappeared, but the peak subsequently reappeared at the same $q_{x y}$ value and with the same shape as that prior to injection of P2. Scans of the Bragg 
peak as a function of time after injection of $\mathrm{P} 3$ at $10 \mu \mathrm{M}$ are shown in Figure 12a. Normalized peak intensity is plotted as a function of time after injection in Figure 12b. In contrast to the results for P2, binding of P3 had little or no detectable effect on the packing of the DSIDA tails in gel phase.

\section{Discussion}

The helical peptides served as simplified versions of proteins with defined structure, functionality positioning, and sufficient flexibility to synergistically interact with the lipid membrane to influence structure and organization. The peptide series used in this study revealed the role of the number and positioning of specific binding sites on the adsorbed peptide orientation, conformation, surface packing, and on membrane reorganization following binding. Prior to evaluating the adsorbed structures formed by each of the peptides, it was important to characterize the peptide structures in solution. In solution at room temperature, the peptides were partially helical with similar fractional helicity (13-17\%). Upon adsorption to $\mathrm{Cu}^{2+}$-DSIDA membranes, the data indicate that very different structures formed for the different peptides (illustrated in Figure 13), and for one peptide (P3), different structures resulted for the same final condition achieved by a different sequence of steps. This latter result indicates that the adsorbed layer was not in equilibrium with the bulk solution. Indeed, through dilution of the subphase, we showed that binding of $\mathrm{P} 3$ to $\mathrm{Cu}^{2+}$-DSIDA was irreversible with respect to bulk peptide concentration at room temperature.

For $\mathrm{P} 2$, the CD data indicate $~ 31 \%$ helicity for $\mathrm{P} 2$ bound to liposomes. The peptides pack to high density, approaching the calculated value for $\alpha$-helices adsorbed side-on at full monolayer coverage. The fact that the thickness values are slightly larger than the diameter of an $\alpha$-helix suggests that the unstructured free ends extend into solution. The fact that adsorption of P2 perturbed the gel phase of the lipid implies that both histidines bound and that they were spatially correlated. This conclusion follows from previous work where protein binding by multiple correlated sites perturbed the gel phase, whereas binding of a protein by a single histidine did not perturb the gel phase. ${ }^{24}$ Correlated binding by the two histidines in P2 implies that they reside within a helical portion of the peptide. We suggest that, even though the peptides are only $17 \%$ helical in solution, for $\mathrm{P} 2$ there is a high probability for the two histidines to reside within a helical portion, since they are closely spaced and are in the central portion of the peptide sequence (illustrated in Figure 13). ${ }^{42}$ We suggest that binding to the membrane locks in the helical conformation between the two histidines and stabilizes helicity in a larger fraction of the bound peptide than exists in the free peptide in solution. This view of an ordered assembly of P2 is supported by the fact that the thickness and adsorbed amount did not depend upon whether the peptide was added incrementally or in a single injection.

The reason for the loss and subsequent recovery of the in-plane diffraction peak upon binding of P2 is not entirely clear. In a hexagonal lattice of close-packed alkyl chains with (10) spacing of $\sim 4.1 \AA$, the closest periodic distance to the histidine separation distance of $\sim 6 \AA$ is $\sim 7.2 \AA$. The lack of precise epitaxy between the lattice of the lipid tails and the distance between histidines may explain the loss of order upon binding. More challenging to explain is the recovery of the lipid gel phase in the presence of the bound peptide. However, GIXD probes the packing of the ordered portion of the lipid tails, whereas the peptide binds to the headgroups which are separated from the tails by a flexible ethylene oxide spacer group. ${ }^{25}$ The spacer group may afford the flexibility for the tails to repack in a hexagonal lattice following peptide binding to the headgroups. This could be examined in future work by altering the length of spacer group.

For P5, binding by a single histidine on the end of the peptide resulted in a much greater thickness $(48 \pm 4)$ than for the other peptides. The CD data indicate that the helical content of 
P5 bound to DSIDA/ $\mathrm{Cu}^{2+}(\sim 17 \%)$ is nearly the same as that for the free peptide $(\sim 14 \%)$. These data are consistent with a densely end-tethered, largely unstructured peptide, as illustrated in Figure 13.

For $\mathrm{P} 3$, the $\mathrm{XR}$ and $\mathrm{CD}$ data indicate that the peptide was far less structured upon adsorption than P2. A much lower coverage was obtained for P3 than for P2, and the thickness and adsorbed amount of the layer depended strongly on the mode of addition. A more unstructured layer for $\mathrm{P} 3$ can be explained by the fact that with histidines spaced $30 \AA$ apart in a peptide of low fractional helicity, the probability that the histidines reside within a helical portion of the peptide, and thus are spatially correlated, is low. The fact that the same thickness and adsorbed amount resulted for $\mathrm{P} 4$ and $\mathrm{P} 3$ is consistent with a lack of spatial correlation of the two histidines in solution in both cases. The His residues were incorporated at different positions on P3 and P4 to place them on the same (P3) or opposite (P4) sides of the helix. However, these spatial correlations were not realized due to the low helicity of these two peptides at room temperature. At lower temperatures where the helical content is increased, we would expect significant differences in the adsorbed layer structures for these two peptides. The low thickness value of $10 \pm 4 \AA$ when the concentration of P3 was slowly increased can be explained by the fact that the unstructured ends are mostly bound to the membrane rather than free as in the case of P2 (illustrated in Figure 13). The fact that a larger thickness for P3 resulted when a high concentration of peptide was added all at once suggests that the two histidines bound sequentially, resulting in a distribution of peptides bound by either one or two histidines. At the higher bulk concentration, presumably a higher fraction of peptides bound by only a single histidine due to crowding by neighboring bound peptides, allowing the free ends to extend further from the surface. ${ }^{43}$ The fact that no perturbation of the lipid packing occurred upon binding of P3 as revealed by GIXD is consistent with either binding by a single histidine or binding of two histidines but without spatial correlation between them. ${ }^{24}$ In comparing the CD data with the reflectivity data, it is important to note that the lipid-to-peptide ratio in the $\mathrm{CD}$ study $(25 / 1)$ was much greater than that in the reflectivity work $(1 / 17$ at $14 \mu \mathrm{M})$. Therefore, we expect the P3 conformation in the CD study to resemble that obtained at the lower P3 concentration in the reflectivity work. The XR data indicate a $10 \pm 4 \AA$ average thickness at the lower P3 concentration, and the CD data indicate a small increase in helical content upon binding compared with that in bulk solution. Together, these data are consistent with a structure in which $\mathrm{P} 3$ is bound to the surface by both ends and only slightly more helical than in solution, as illustrated in Figure 13. The lower helicity (19\% compared to $31 \%$ for P2) and the lack of spatial correlation between the binding sites apparently preclude the peptides from packing densely.

For a given bulk concentration, we observed much slower adsorption kinetics for P5, containing one histidine, than for the peptides with two histidines, even those with the histidines spaced widely apart. We attribute the faster adsorption rate for P2, P3, and P4 relative to P5 to the fact that the two histidines per peptide doubles the probability of a favorable His/ $\mathrm{Cu}^{2+}$ interaction per collision. Also, at partial coverage the extended thickness of an end-tethered structure may provide a more effective barrier to penetration by additional chains than for the other cases.

\section{Conclusions}

We have combined XR, NR, GIXD, and CD to reveal structural characteristics of partially helical peptides adsorbed to lipid monolayers through divalent metal ion-histidine interactions. While the effect of peptide adsorption on the reflectivity was weak, important structural characteristics could still be obtained. Our data suggest that, for the peptide with two histidines spaced $6 \AA$ apart in the center of the sequence, both sites bind in a spatially correlated manner and the helical character of the peptide increases substantially upon adsorption. This results in high-density packing in a side-on orientation with unstructured ends that extend into solution. 
On the other hand, the peptides with two histidines spaced $30 \AA$ and $26 \AA$ apart (P3 and P4) are far less structured upon adsorption, and the two histidines bind sequentially and are spatially uncorrelated in those cases. We attribute this to the fact that a single His/Cu/IDA interaction is irreversible at room $T$, and that for these partially helical peptides the probability for spatial correlation of the two histidines in solution at room temperature decreases with increasing separation along the backbone. The result was a much lower packing density, and a thickness that was dependent on the mode of addition of the peptide (incremental or all at once). We have also demonstrated control over the orientation of the bound peptides. Placing a histidine on an end of the sequence led to adsorbed peptides oriented perpendicular to the membrane. These approaches and molecular systems may provide strategies for controlling peptide orientation and the kinetics of adsorption to membranes in the development of nanostructured materials and devices.

\section{Supplementary Material}

Refer to Web version on PubMed Central for supplementary material.

\section{Acknowledgments}

Sandia is a multiprogram laboratory operated by Sandia Corporation, a Lockheed Martin Company, for the United States Department of Energy under contract DE-AC04-94AL85000. The project was supported in part by grants 1P20-RR17716-01 and 5-P20-RR015588 (instrument facilities) from the National Center for Research Resources (NCRR), a component of the National Institutes of Health (NIH) and also by the National Science Foundation (DMR 0239744). Its contents are solely the responsibility of the authors and do not necessarily represent the official views of NCRR or NIH. We also acknowledge the support of the National Institute of Standards and Technology, U.S. Department of Commerce, in providing X-ray and neutron research facilities for this work.

\section{References}

1. Arnold FH. Biotechnology (NY) 1991;9(2):151-6.

2. Lata S, Gavutis M, Piehler J. J Am Chem Soc 2006;128(1):6-7. [PubMed: 16390094]

3. Celia H, Wilson-Kubalek E, Milligan RA, Teyton L. Proc Natl Acad Sci USA 1999;96(10):5634-9. [PubMed: 10318936]

4. Kinnunen PKJ, Koiv A, Lehtonen JYA, Rytömaa M, Mustonen P. Chem Phys Lipids 1994;73:181207. [PubMed: 8001181]

5. Kolter T, Winau F, Schaible UE, Leippe M, Sandhoff K. J Biol Chem 2005;280:41125-41128. [PubMed: 16230343]

6. Zhang X, Keiderling TA. Biochemistry 2006;45:8444-8452. [PubMed: 16819842]

7. Dietrich C, Boscheinen O, Scharf KD, Schmitt L, Tampe R. Biochemistry 1996;35(4):1100-5. [PubMed: 8573564]

8. Dietrich C, Schmitt L, Tampe R. Proc Natl Acad Sci USA 1995;92(20):9014-8. [PubMed: 7568063]

9. Haas H, Brezesinski G, Mohwald H. Biophys J 1995;68(1):312-4. [PubMed: 7711256]

10. Courty SLL, Martel L, Lenne PF, Balavoine F, Dischert W, Konovalov O, Mioskowski C, Legrand JF, Venien-Bryan C. Langmuir 2002;18:9502-9512.

11. Venien-Bryan C, Lenne PF, Zakri C, Renault A, Brisson A, Legrand JF, Berge B. Biophys J 1998;74 (5):2649-57. [PubMed: 9591688]

12. Maloney K, Shnek D, Sasaki D, Arnold F. Chem Biol 1996;3(3):185-92. [PubMed: 8807844]

13. Pack DWNK, Maloney KM, Arnold FH. Supramol Sci 1996;4:3-10.

14. Frey W, Schief WR Jr, Pack DW, Chen CT, Chilkoti A, Stayton P, Vogel V, Arnold FH. Proc Natl Acad Sci USA 1996;93(10):4937-41. [PubMed: 8643507]

15. Shnek D, RP, DW, Sasaki DY, Arnold FH. Langmuir 1994;10:2382-2388.

16. Mallik SJ, RD, Arnold FH. J Am Chem Soc. 1994

17. Ng KP, DW, Sasaki DY, Arnold FH. Langmuir 1995;11:4048. 
18. Bischler N, Balavoine F, Milkereit P, Tschochner H, Mioskowski C, Schultz P. Biophys J 1998;74 (3):1522-32. [PubMed: 9512048]

19. Radler U, Mack J, Persike N, Jung G, Tampe R. Biophys J 2000;79(6):3144-52. [PubMed: 11106619]

20. Lee S, Yoshitomi H, Morikawa M, Ando S, Takiguchi H, Inoue T, Sugihara G. Biopolymers 1995;36 (3):391-8. [PubMed: 7669922]

21. Kiyota T, Lee S, Sugihara G. Biochemistry 1996;35(40):13196-204. [PubMed: 8855958]

22. Dathe M, Schumann M, Wieprecht T, Winkler A, Beyermann M, Krause E, Matsuzaki K, Murase O, Bienert M. Biochemistry 1996;35(38):12612-22. [PubMed: 8823199]

23. Deber CM, Li SC. Biopolymers 1995;37(5):295-318. [PubMed: 7632880]

24. Yim H, Kent MS, Sasaki DY, Polizzotti BD, Kiick KL, Majewski J, Satija S. Phys Rev Lett 2006;96 (19):198101. [PubMed: 16803142]

25. Kent MS, Yim H, Sasaki DY, Satija S, Majewski J, Gog T. Langmuir 2004;20(7):2819-29. [PubMed: 15835159]

26. Kent MS, Yim H, Sasaki DY, Satija S, Seo YS, Majewski J. Langmuir 2005;21(15):6815-24. [PubMed: 16008391]

27. Russell T. Mater Sci Rep 1990;5:171-271.

28. Als-Nielsen J, Jacquemain D, Kjaer K, Leveiller F, Lahav M, Leiserowitz L. Phys Rep 1994;246:251313.

29. Kjaer K. Physica B 1994;198:100-109.

30. Jensen, TR.; Kjaer, K. Novel Methods to Study Interfacial Layers, Studies in Interface Science. Vol. II. Elsevier Science; Amsterdam: 2001. Structural properties and interactions of thin films at the airliquid interface explored by synchrotron X-ray scattering; p. 205-254.

31. Cochran DA, Penel S, Doig AJ. Protein Sci 2001;10:463-470. [PubMed: 11344315]

32. Farmer RS, Kiick KL. Biomacromolecules 2005;6:1531-1539. [PubMed: 15877375]

33. Marqusee S, Baldwin RL. Proc Natl Acad Sci USA 1987;84:8898-8902. [PubMed: 3122208]

34. Scholtz JM, Baldwin RL. Annu Rev Biophys Biomol Struct 1992;21:95-118. [PubMed: 1525475]

35. Shalongo W, Dugad L, Stellwagen E. J Am Chem Soc 1994;116:8288-8293.

36. Merutka G, Shalongo W, Stellwagen E. Biochemistry 1991;30:4245-4248. [PubMed: 2021618]

37. Miller JS, Kennedy RJ, Kemp DS. J Am Chem Soc 2002;124:945-962. [PubMed: 11829602]

38. Scholtz JM, Marqusee S, Baldwin RL, York EJ, Stewart JH, Santoro M, Bolen DW. Proc Natl Acad Sci USA 1991;88:2854-2858. [PubMed: 2011594]

39. Kennedy RJ, Tsang KY, Kemp DS. J Am Chem Soc 2002;124:934-944. [PubMed: 11829601]

40. Douglas JF, Schneider HM, Frantz P, Lipman R, Granick S. J Phys: Condens Matter 1997;9:7699_ 7718.

41. O’Shaughnessy B, Vavylonis D. Phys Rev Lett 2003;90:056103. [PubMed: 12633380]

42. Chakrabartty A, Baldwin RL. Adv Protein Chem 1995;46:141-76. [PubMed: 7771317]

43. Schneider HM, Frantz P, Granick S. Langmuir 1996;12:994-996. 


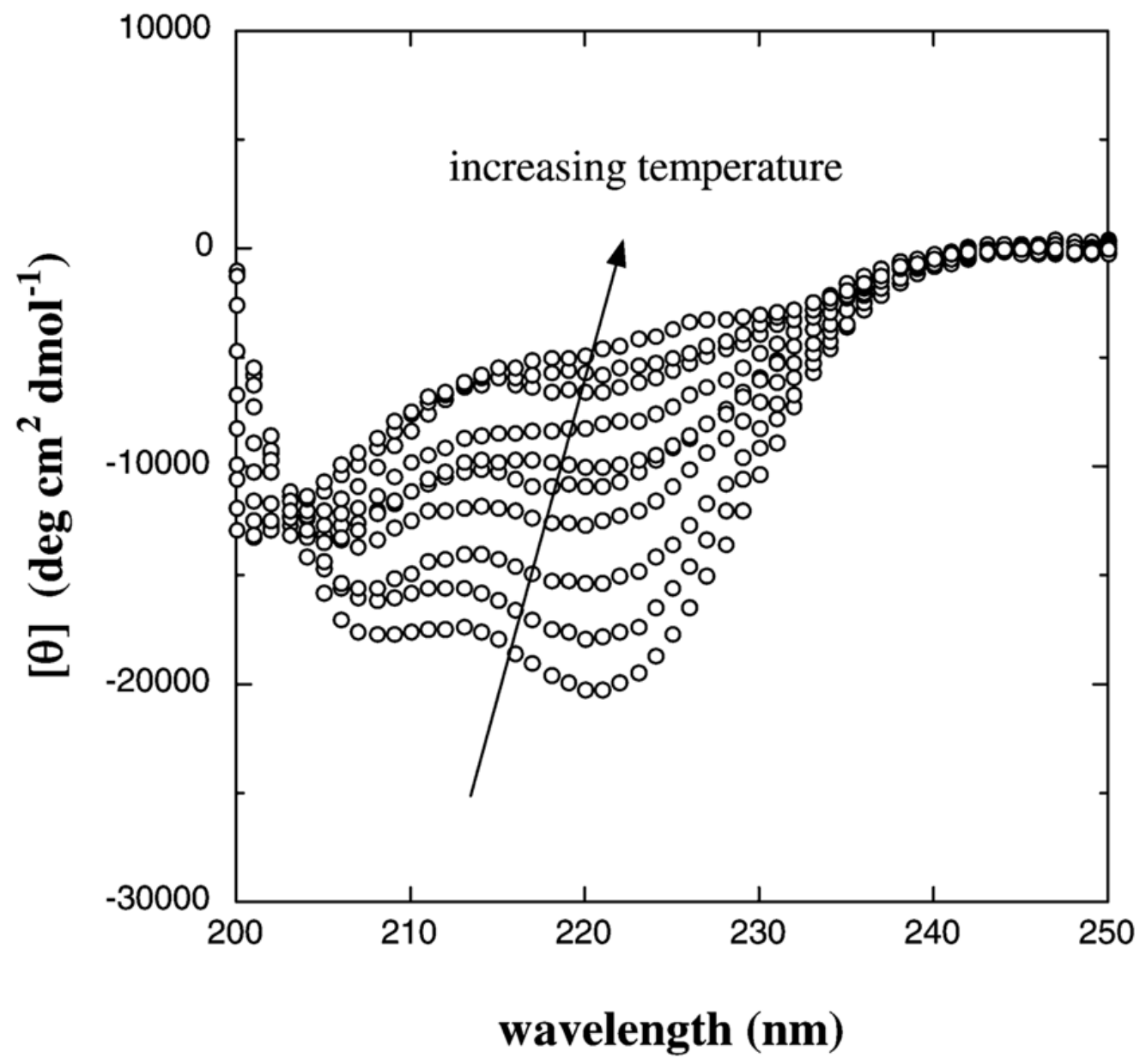

Figure 1.

Circular dichroic spectra of $\mathrm{P} 2(15 \mu \mathrm{M})$ in $10 \mathrm{mM}$ phosphate buffer $\mathrm{pH}$ 7.2. CD spectra were collected in increments of $5^{\circ} \mathrm{C}$ over the range $5-50{ }^{\circ} \mathrm{C}$. 
a)

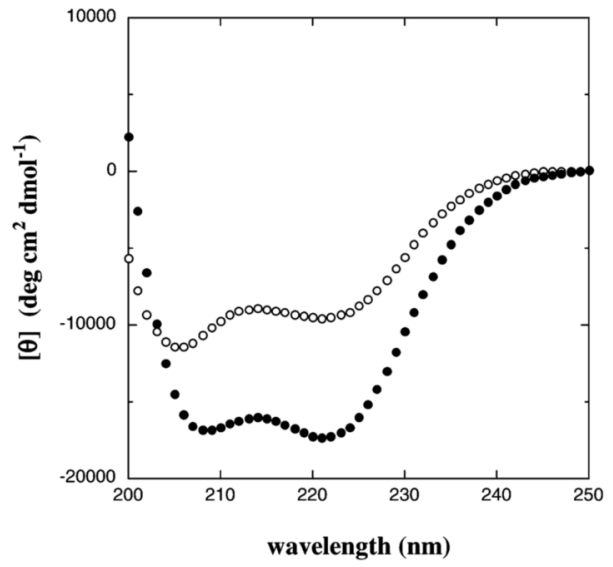

b)

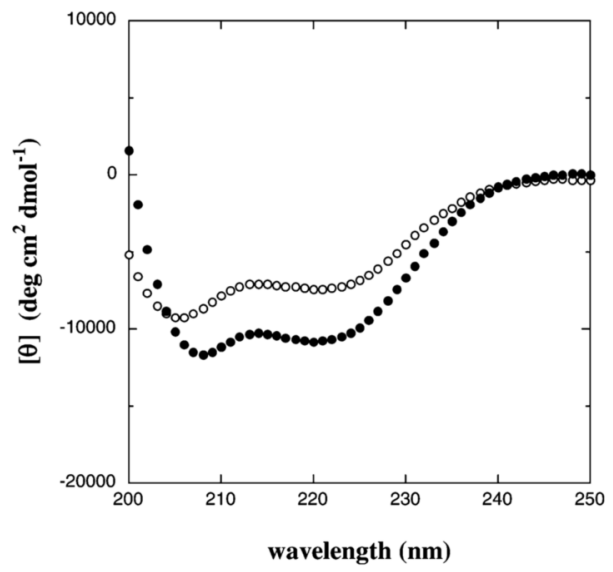

c)

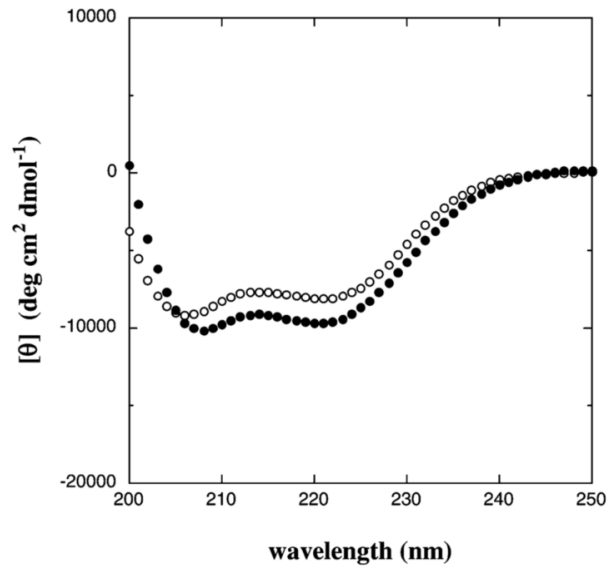

Figure 2.

CD spectra acquired after $20 \mathrm{~h}$ at $22^{\circ} \mathrm{C}$ for (a) P2, (b) P3, and (c) P5 in the absence (O) and presence $(\bullet)$ of DSIDA/ $\mathrm{Cu}^{2+}$ liposomes. These data indicate that a much greater increase in fractional helicity upon binding to the liposomes occurs for P2 than for P3, and that very little change occurs for P5. 

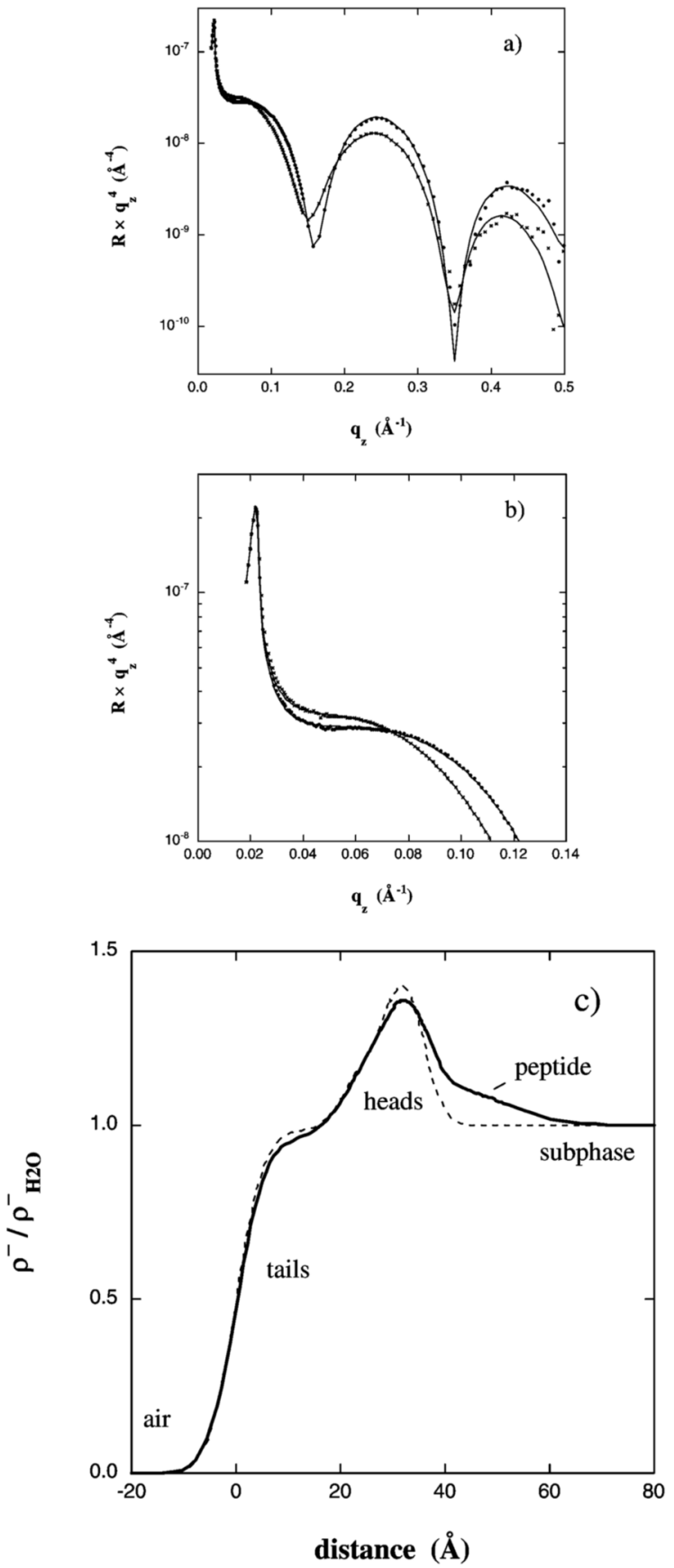

Figure 3.

(a) XR before $(\bullet)$ and after $(x)$ adsorption of P2 at $14 \mu \mathrm{M}$. (b) Expanded view of the low $\mathrm{q}_{z}$ region. (c) Normalized electron density profile corresponding to the data in (a). 

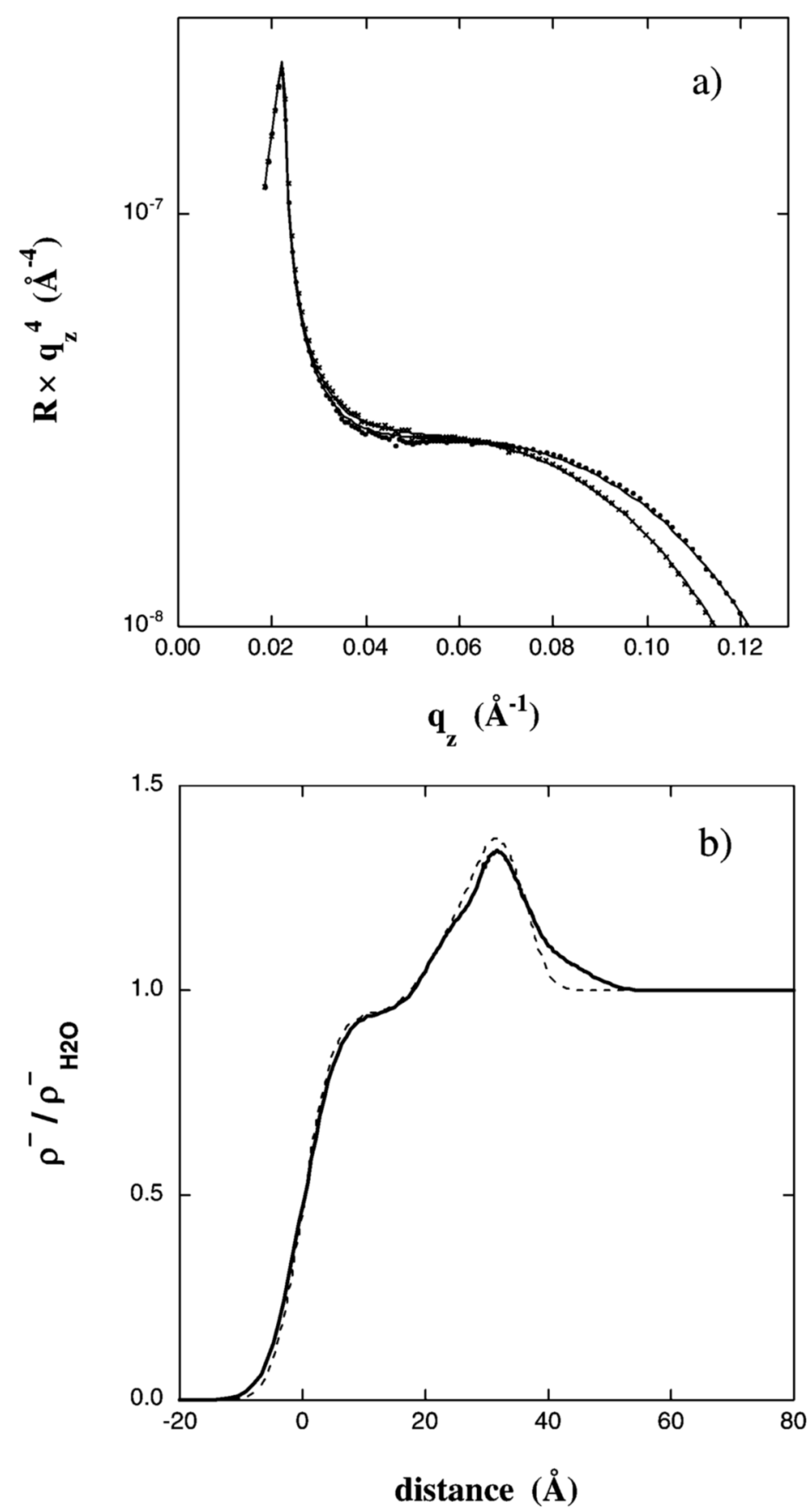

Figure 4.

(a) XR before $(\bullet)$ and after $(\times)$ adsorption of P3 at $14 \mu \mathrm{M}$, where the peptide was added in successive additions to reach the final concentration (expanded view of the low $\mathrm{q}_{z}$ region-the full curves are available in Figure 2 of the Supporting Information). (b) Normalized electron density profile corresponding to the data in (a). 

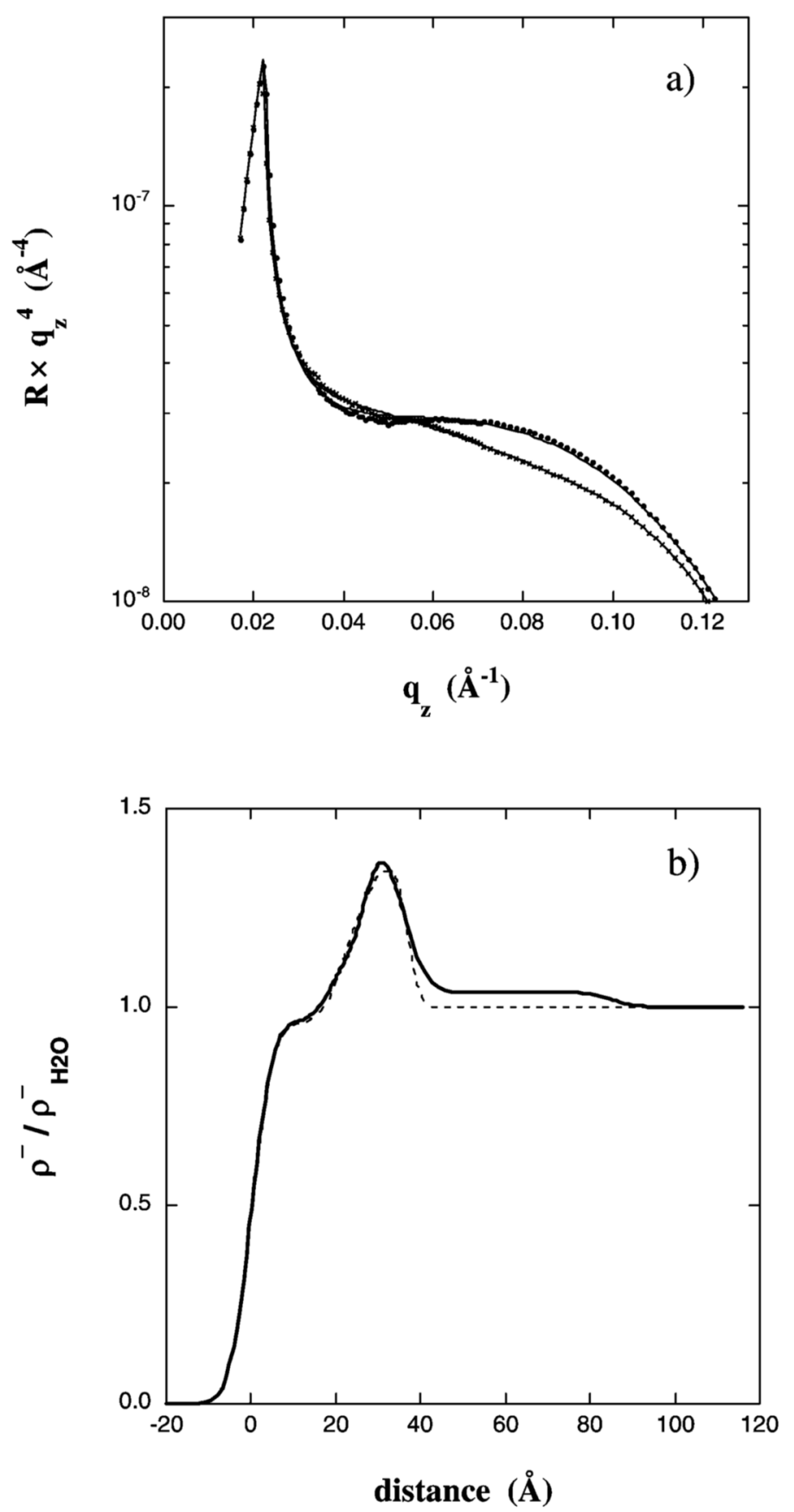

Figure 5.

(a) XR before $(\bullet)$ and after $(\times)$ adsorption of P5 at $10 \mu \mathrm{M}$ (expanded view of the low $\mathrm{q}_{z}$ regionthe full curves are available in Figure 3 of the Supporting Information). (b) Normalized electron density profile corresponding to the data in (a). 


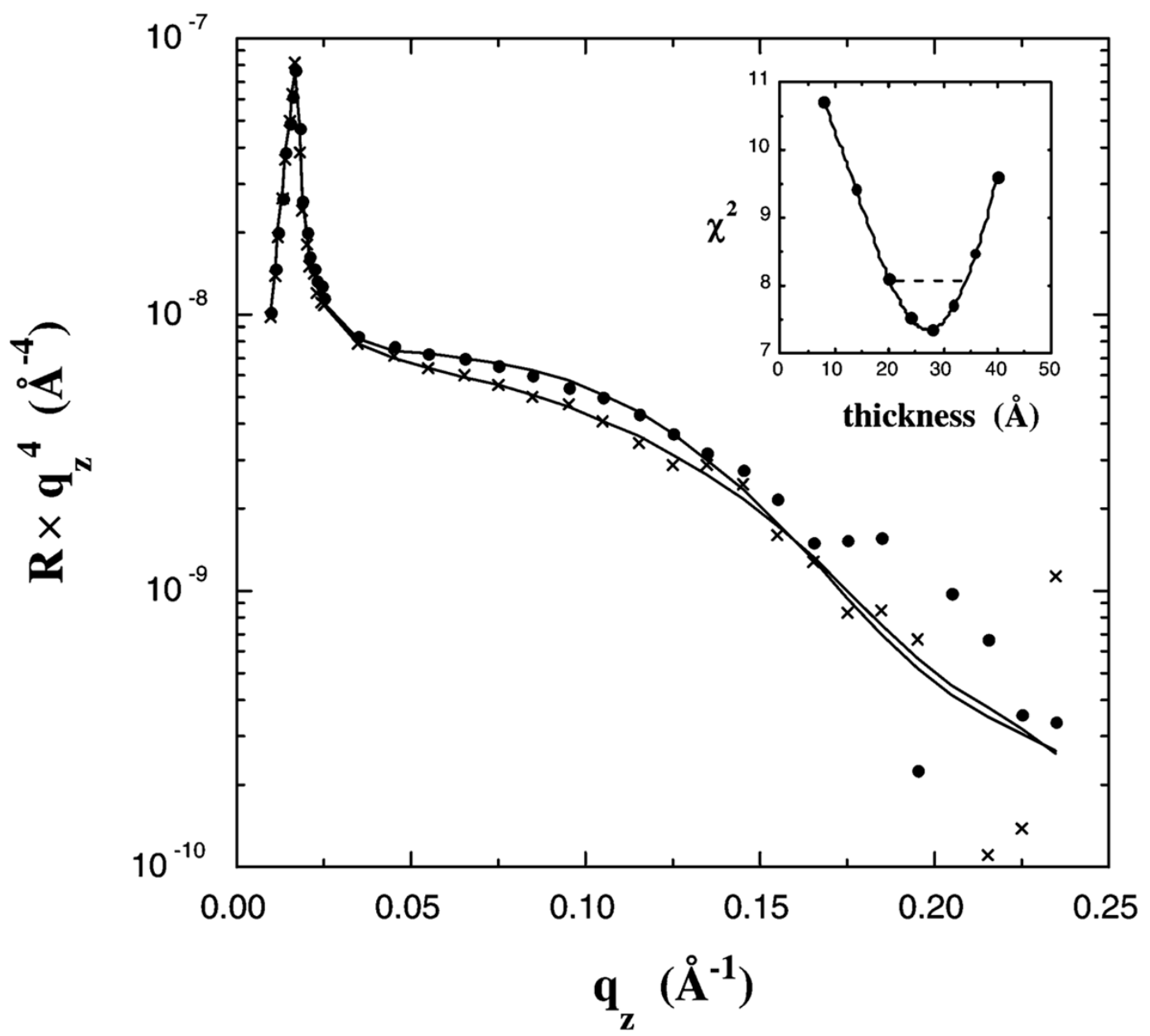

Figure 6.

NR before $(\bullet)$ and after $(\times)$ adsorption of P3 at $14 \mu \mathrm{M}$, where the entire mass of peptide was injected at the start. The inset shows $\chi^{2}$ vs thickness from the fitting analysis, yielding a thickness of $27 \pm 7 \AA$. 


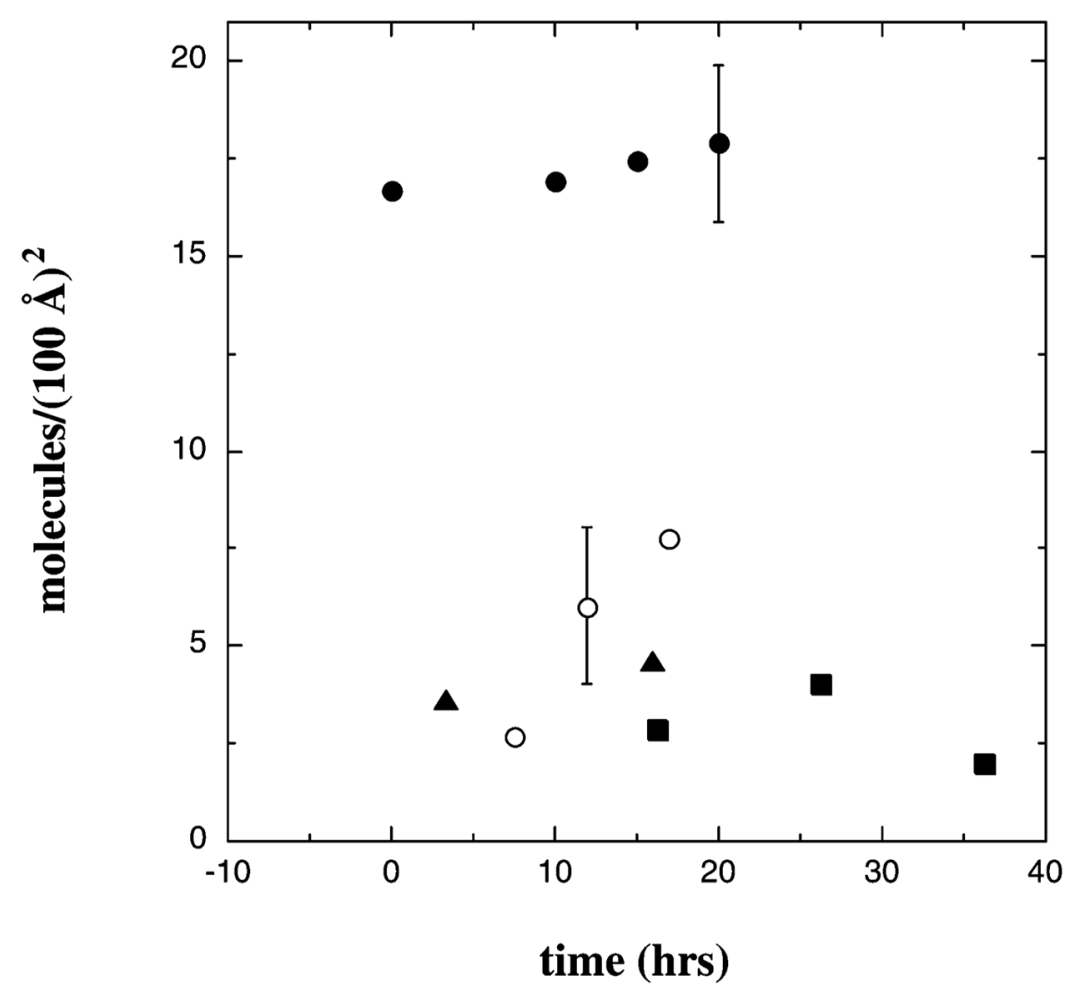

Figure 7.

Adsorbed amount for P2 at $4 \mu \mathrm{M}(\mathrm{\circ})$ and $14 \mu \mathrm{M}(\bullet), \mathrm{P} 3$ at $4 \mu \mathrm{M}(\boldsymbol{\Delta})$, and P4 at $4 \mu \mathrm{M}(\boldsymbol{\bullet})$. 


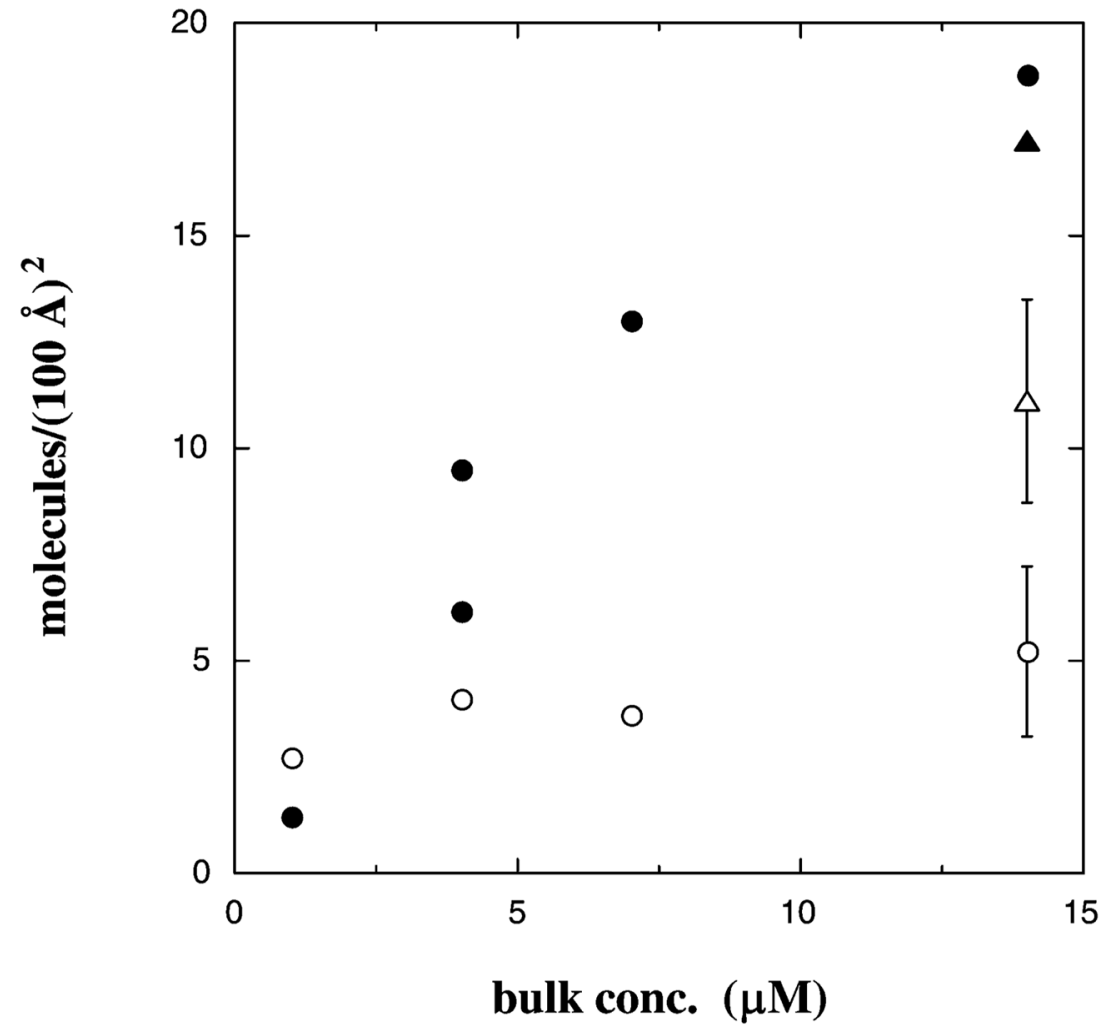

Figure 8.

Adsorbed amount vs bulk concentration for P2 $(\bullet)$ and P3 (•) for successive additions, and for P2 $(\boldsymbol{\Delta})$ and P3 $(\Delta)$ added to $14 \mu \mathrm{M}$ in one injection. For the incremental additions, the dwell time at each concn was $\sim 3 \mathrm{~h}$ as required for the XR scans. 

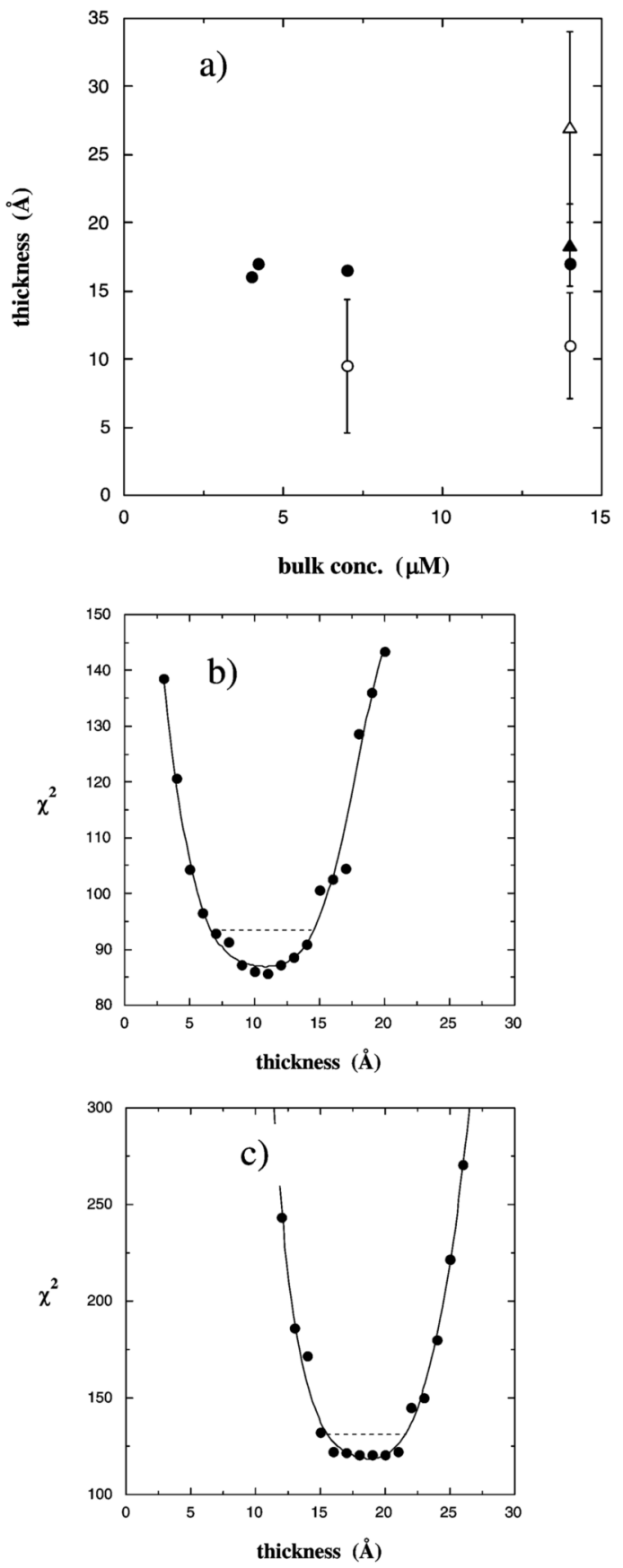

Figure 9.

(a) Thickness vs bulk concentration for P2 (•) and P3 (०) added incrementally, and for P2 ( $\bullet$ ) and P3 $(\Delta)$ at $14 \mu \mathrm{M}$ added in a single injection. Error bars were determined from the fitting analysis by fixing the thickness at particular values and allowing the other parameters to vary within physically reasonable limits. Upper and lower bounds were determined by the thickness values that led an increase in $\chi^{2}$ by a factor of 1.1. Examples are shown in (b) for P3 at $14 \mu \mathrm{M}$ and in (c) for P2 at $14 \mu \mathrm{M}$. 


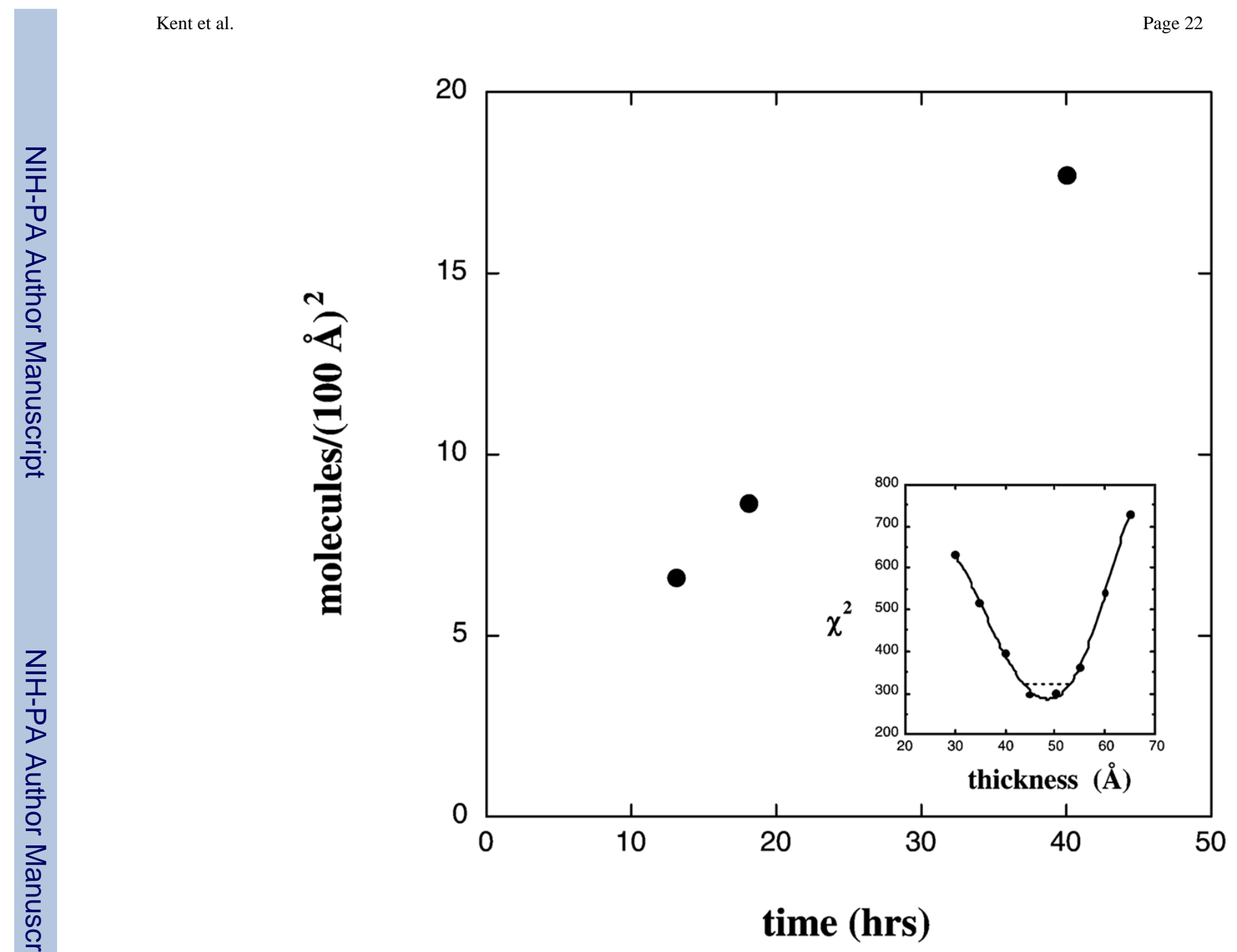

Figure 10.

Adsorbed amount vs time after injection of P5. The inset shows the $\chi^{2}$ plot for the data at 40 $\mathrm{h}$ which demonstrates that the thickness upon adsorption of P5 is substantially greater than that for P2. 

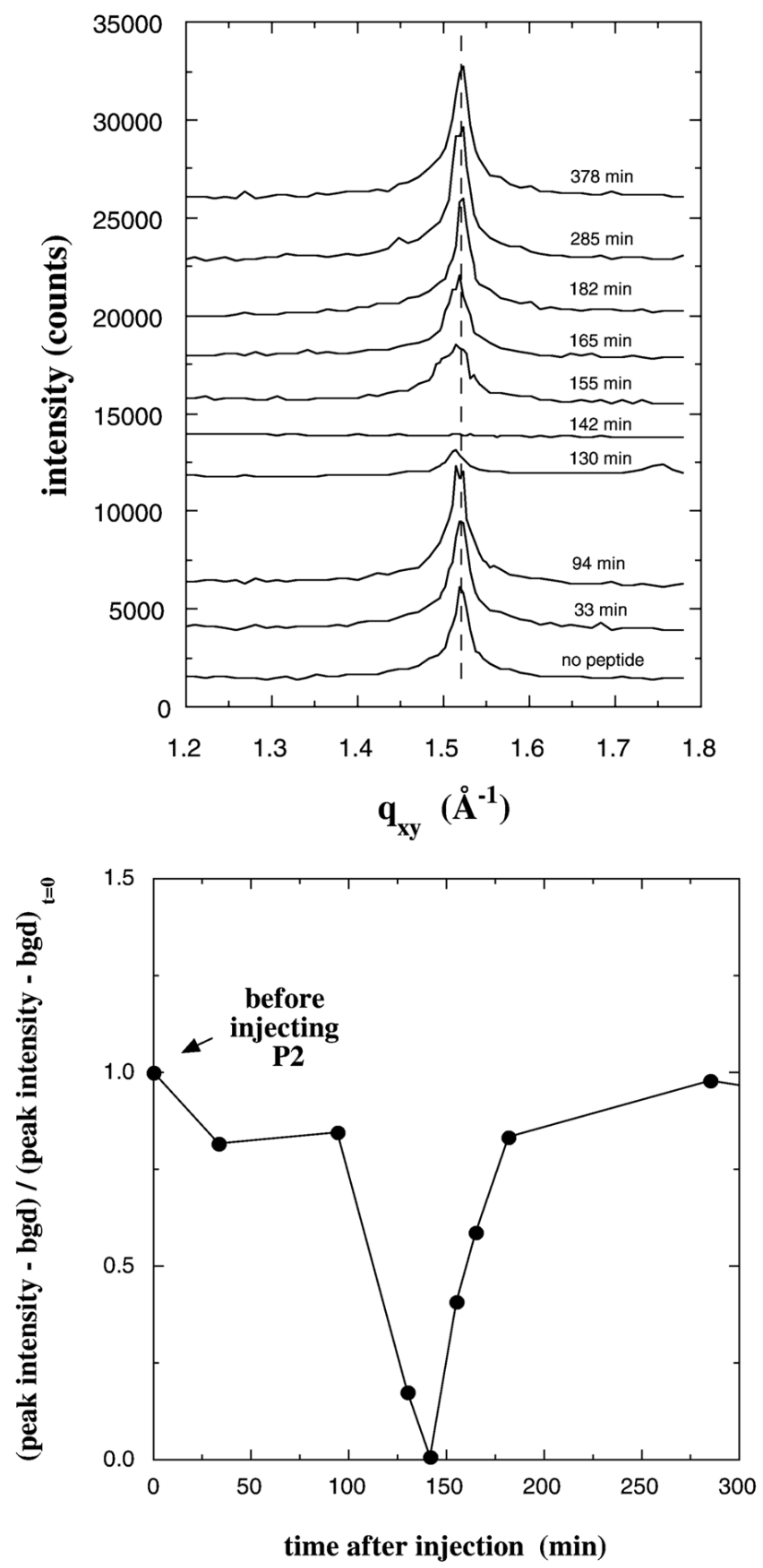

Figure 11.

(a) Bragg peaks for films of DSIDA/Cu ${ }^{2+}$ prior to injecting $\mathrm{P} 2$, and as a function of time after injection for a surface pressure of $40 \mathrm{mN} / \mathrm{m}$. (b) Normalized peak intensity vs time after injecting P2. 

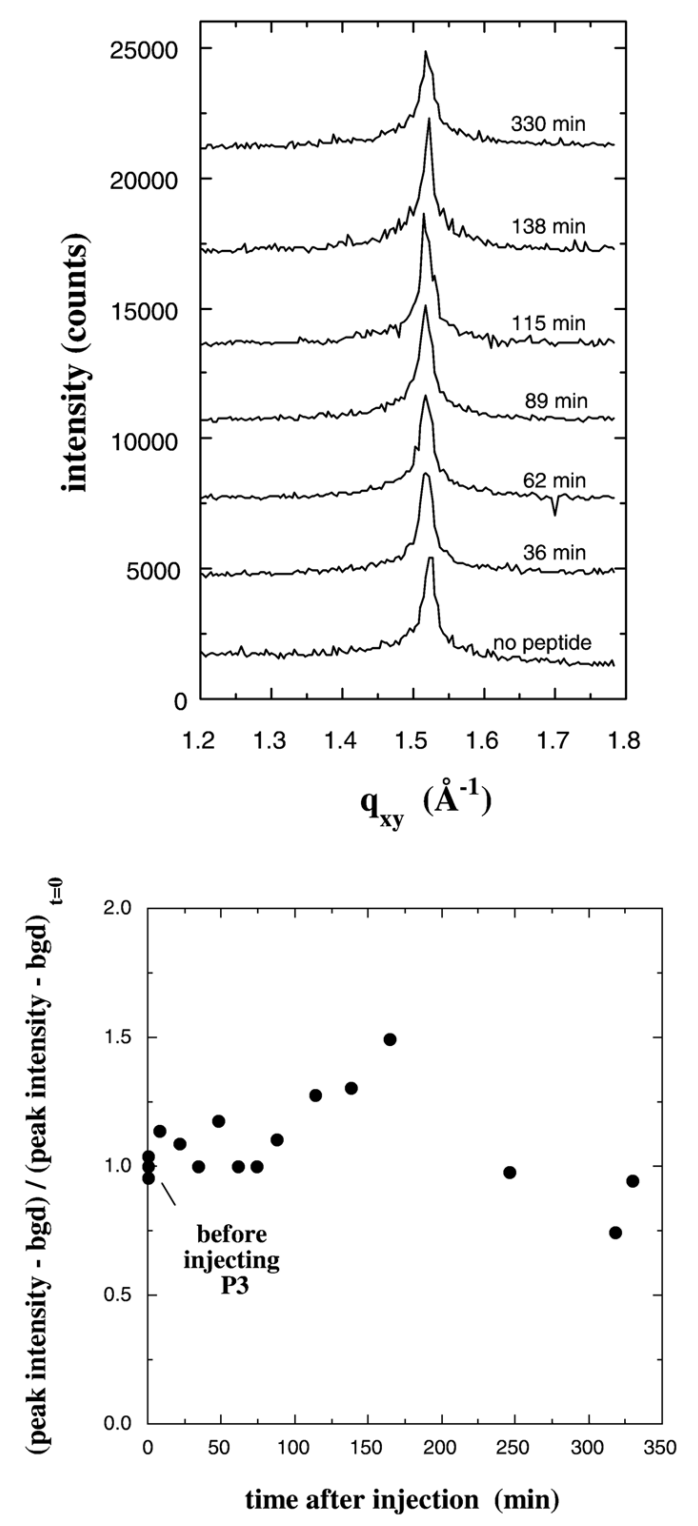

Figure 12.

(a) Bragg peaks from GIXD for films of DSIDA/Cu ${ }^{2+}$ prior to injecting P3, and at different times after injection for a surface pressure of $40 \mathrm{mN} / \mathrm{m}$. (b) Normalized peak intensity vs time after injecting P3. 


\section{P2-lipid film association}

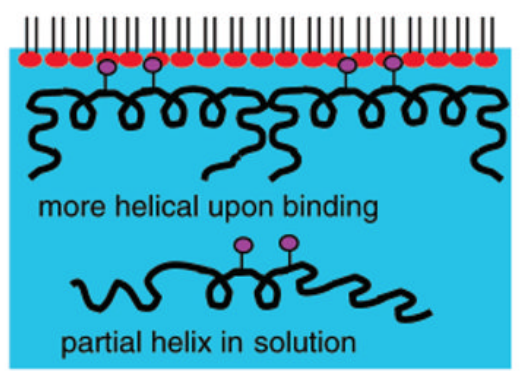

\section{P3-lipid film association}

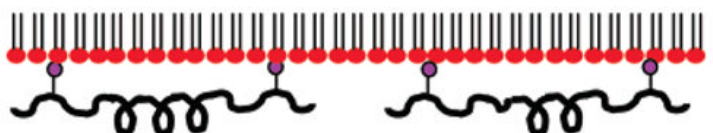

low peptide concentration

\section{P5-lipid film association}
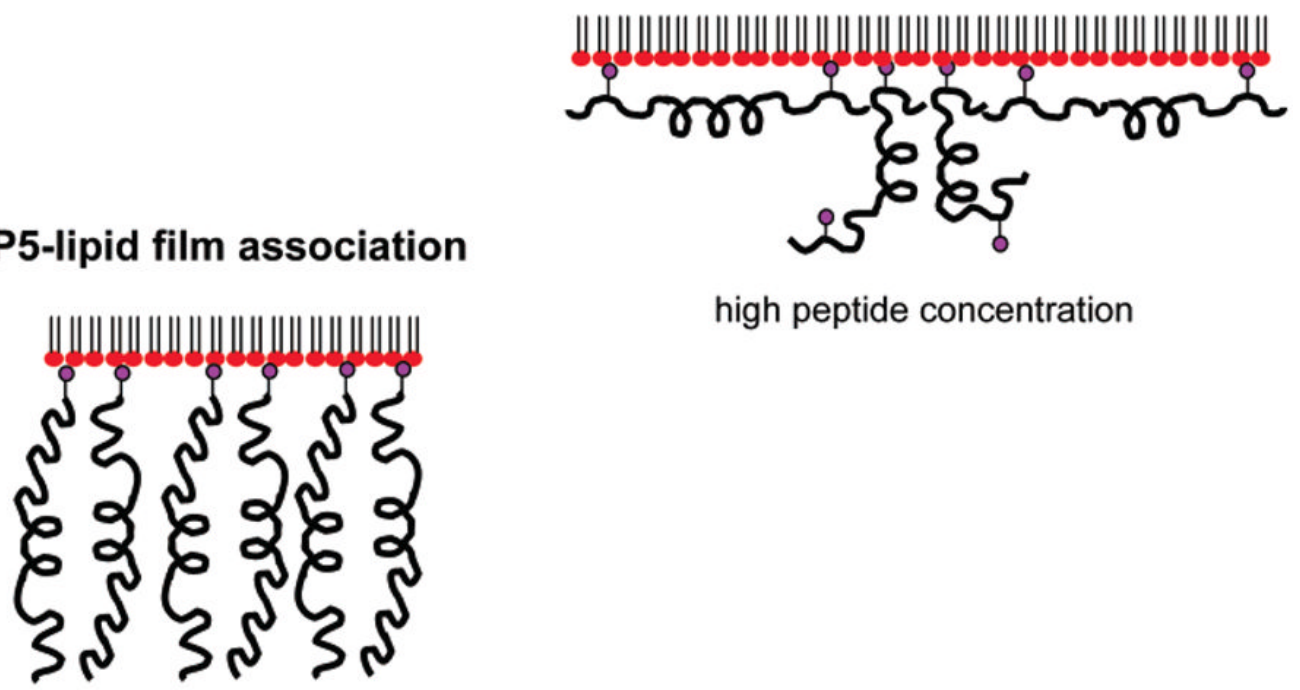

high peptide concentration

Figure 13.

Illustrations of adsorbed structures for P2, P3, and P5 consistent with the results of this study. 


\section{Table 1}

List of Histidine-Containing Peptides Used in the Present Study, Their Respective Sequence, Nominal Distance between Adjacent Histidine Residues, and Orientation

\begin{tabular}{ccccc}
\hline peptide & sequence & $\begin{array}{c}\text { distance between } \\
\text { adjacent histidine } \\
\text { residues (A) }\end{array}$ & $\begin{array}{c}\text { histidine positioning along } \\
\text { helix backbone }\end{array}$ \\
\hline P1 & Ac-QAAAQAAQAAAAQAAAAQAAAQAAAAQAAQGGW-Am & & 6 & same face \\
P2 & Ac-QAAQAAAAQAAAAHAAAHAAAAQAAAAQAAQGGW-Am & 30 & 26 & same face \\
P3 & Ac-QAAAAHAAQAAAAQAAAAQAAQAAHAAAAQGGW-Am & & \\
P4 & Ac-QAAAAHAAQAAAAQAAAAQAAAHAAAAQAAQGGW-Am & &
\end{tabular}

